\title{
Prioritizing Public Value in the Changing Mobility Landscape
}

\section{Citation}

Goldsmith, Stephen, and Betsy Gardner. "Prioritizing public value in the changing mobility landscape." Mobility and the Connected City Series, Harvard University, Cambridge, MA, 2020.

\section{Published Version}

https://ash.harvard.edu/publications/prioritizing-public-value-changing-mobility-landscape

\section{Permanent link}

http://nrs.harvard.edu/urn-3:HUL.InstRepos:42556711

\section{Terms of Use}

This article was downloaded from Harvard University's DASH repository, and is made available under the terms and conditions applicable to Other Posted Material, as set forth at http:// nrs.harvard.edu/urn-3:HUL.InstRepos:dash.current.terms-of-use\#LAA

\section{Share Your Story}

The Harvard community has made this article openly available.

Please share how this access benefits you. Submit a story.

Accessibility 
Mobility and the Connected City

\section{Prioritizing Public Value in the Changing Mobility Landscape}

Stephen Goldsmith and Betsy Gardner

January 2020 
Mobility and the Connected City

\section{Prioritizing Public Value in the Changing Mobility Landscape}

Stephen Goldsmith and Betsy Gardner

January 2020

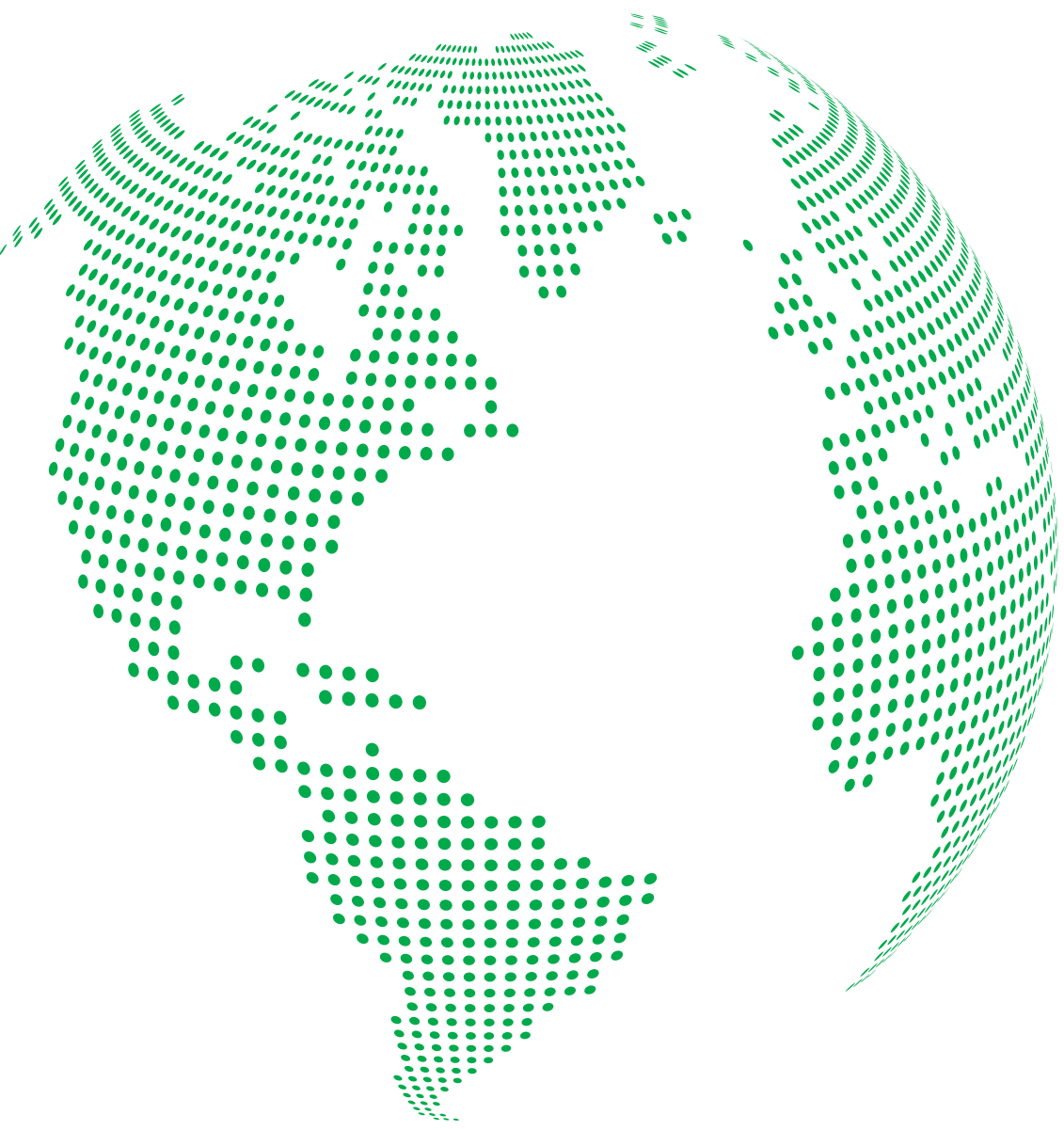




\section{ABOUT THE AUTHORS}

Stephen Goldsmith is the Daniel Paul Professor of the Practice of Government and the director of the Innovations in American Government Program at Harvard Kennedy School. He currently directs Data-Smart City Solutions, a project to highlight local government efforts to use new technologies that connect breakthroughs in the use of big data analytics with community input to reshape the relationship between government and citizen. He previously served as deputy mayor of New York and mayor of Indianapolis, where he earned a reputation as one of the country's leaders in public-private partnerships, competition, and privatization. Stephen was also the chief domestic policy advisor to the George W. Bush campaign in 2000, the chair of the Corporation for National and Community Service, and the district attorney for Marion County, Indiana from 1979 to 1990. He has written The Power of Social Innovation; Governing by Network: the New Shape of the Public Sector; Putting Faith in Neighborhoods: Making Cities Work through Grassroots Citizenship; The Twenty-First Century City: Resurrecting Urban America; The Responsive City: Engaging Communities Through Data-Smart Governance; and, most recently, A New City O/S: The Power of Open, Collaborative, and Distributed Governance.

Betsy Gardner is a research assistant and writer for Digital Platforms and Practitioner Content for the Innovations in Government Program at Harvard Kennedy School's Ash Center. Prior to joining the Center, Betsy was a Research Assistant at the Lincoln Institute of Land Policy and Assistant Director of Training at Northeastern University. Her professional and volunteer work promotes racial and gender equality through research, writing, and facilitation. She has delivered talks for audiences such as Major League Baseball, the MIT Sloan School of Management, and the Smart Citizenship Academy in Cascais, Portugal. Betsy holds a master's degree in Urban and Regional Policy from Northeastern University and a bachelor's degree in Art History from Boston University. 


\section{ABOUT THE ASH CENTER}

The Roy and Lila Ash Center for Democratic Governance and Innovation advances excellence and innovation in governance and public policy through research, education, and public discussion. By training the very best leaders, developing powerful new ideas, and disseminating innovative solutions and institutional reforms, the Center's goal is to meet the profound challenges facing the world's citizens. The Ford Foundation is a founding donor of the Center. Additional information about the Ash Center is available at ash.harvard.edu.

This research paper is one in a series published by the Ash Center for Democratic Governance and Innovation at Harvard University's John F. Kennedy School of Government. The views expressed in the Ash Center Policy Briefs Series are those of the author(s) and do not necessarily reflect those of the John F. Kennedy School of Government or of Harvard University. The papers in this series are intended to elicit feedback and to encourage debate on important public policy challenges.

\section{ACKNOWLEDGEMENTS}

Financial support for this paper was generously provided by the John S. and James L. Knight Foundation, which played no role in shaping the findings presented. 


\section{CONTENTS}

$\begin{array}{ll}\text { Introduction } & 1\end{array}$

Executive Summary 2

Connected Mobility Conference 2

What Changed-How Did We Get Here? $\quad 4$

1. The Impact of Connectivity on Mobility 4

2. Return to Cities, Gentrification; Movement Away from Jobs 5

3. E-Commerce and Delivery 7

4. Effect of Digital Maps 8

5. Recognition of High Cost of Parking and the Value of the Curb 8

$\begin{array}{lr}\text { What's at Stake: Public Value Goals and Mobility } & 10\end{array}$

$\begin{array}{ll}\text { Community Engagement and a User-Centric Design } & 10\end{array}$

$\begin{array}{ll}\text { Improved Public Safety } & 12\end{array}$

$\begin{array}{ll}\text { Improving Public Health and Sustainability } & 13\end{array}$

$\begin{array}{ll}\text { Advancing Equitable Service Delivery and Access } & 16\end{array}$

$\begin{array}{ll}\text { Improving Land-Use Planning and Parking Policy } & 17\end{array}$

$\begin{array}{ll}\text { What's at Stake } & 19\end{array}$

$\begin{array}{lr}\text { Next Steps } & 19\end{array}$

$\begin{array}{lr}\text { Appendix: Conference Attendees } & 20\end{array}$ 


\section{INTRODUCTION}

Streets and their sidewalks-the main public places of a city-are its most vital organs.

-Jane Jacobs

As vital organs of the city, streets and sidewalks not only move people but bring them together. When well designed and operated, they support commerce, encourage social capital, enable healthy behaviors such as biking and walking, and produce cleaner air. Conversely, these vital organs, when poorly designed or managed, can encourage activities that result in substantial negative externalities, including increased safety concerns as cars collide with bikes and scooters with pedestrians.

Technological advancements have changed how a city's residents and officials experience connectedness. People use social media to share experiences and information. Sophisticated municipal data officers use mapping and data tools to respond with more specificity to the needs of a family or neighborhood. Private companies use platforms to facilitate new shared mobility options. Yet city agencies still too often act independently. Connectedness-neighbor to neighbor or worker to job-requires new policies, governance structures, and operating models or these organisms will no longer be so vital.

Indeed, not only do cities and regions currently disperse transit management across too many departments, they rarely focus on the consumer and do not fully value streets and sidewalks as public assets when making decisions about land use, sustainability, public safety, and employment.

These municipal tradeoffs can often explode into the public realm around a particular problem such as municipal interaction with transportation network companies (TNCs) and shared micromobility providers of bicycles and scooters. The policy and regulation vacuum, produced when regulation lags behind innovation, can result in cities turning sidewalks and avenues over to the boldest commercial provider of shared mobility. Lack of consensus about the broader goals of transit management 
and regulation results in a patchwork of responses and an asymmetry of negotiating power between vendors and a city.

In this new mobility world, one could even argue that streets and sidewalks are not even public goods in the classic sense, which defines such a good as one where consumption by one individual does not reduce its availability or exclude others from consuming it. Tradeoffs exist in planning, but they need to be made with a clearer set of choices-bus rapid transit lanes slow down other vehicles; micromobility vehicles can clutter pedestrian spaces. Understanding the purposes of streets and sidewalks will sharpen the focus on how to create a broader narrative that produces positive results for the common good consistent with a clear definition of public value.

\section{Executive Summary}

In this paper we will look at the values and goals cities affect with policies concerning connected mobility, and how to create a new framework that aligns with these objectives. First, we identify the transformative changes affecting cities and mobility. Second, we discuss in more detail the guiding values and goals that cities have around mobility with examples of these values in practice. Our next paper, Effectively Managing Connected Mobility Marketplaces, discusses the different regulatory approaches that cities can leverage to achieve these goals.

We recommend that cities identify various public values, such as Equity or Sustainability, and use these to shape their transit policy. Rather than segmenting the rapidly changing mobility space, cities should take advantage of the interconnectivity of issues like curb space management, air quality, and e-commerce delivery to guide public policy. Cities must establish a new system to meet the challenges and opportunities of this new landscape, one that is centered around common values, prioritizes resident needs, and is informed by community engagement.

In conclusion, cities must use specific public values lenses when planning and evaluating all the different facets of mobility. Transportation has entered a new phase, and we believe that cities should move forward with values- and community-driven policies that frame changing mobility as an opportunity to amend and improve previous transportation policies. 


\section{Connected Mobility Conference}

This paper benefits from a set of astute observations shared by those attending the Future of Connected Mobility conference at the John F. Kennedy School of Government at Harvard University in October 2019, organized with the support of the Knight Foundation. The conclusions in this paper are those of the authors, informed by the comments of those attending, and should not be considered the views of any specific attendee or of the funder unless directly attributed.

According to Lilian Coral, director of National Strategy + Technology Innovation at the Knight Foundation, the basis for much of the foundation's work is increasing community responsiveness and engagement. Knight believes that people in smart cities need to be informed and engaged in the transformation of their cities and public spaces. The Future of Connected Mobility conference emerged from the intersection of Knight's interest in autonomous vehicles, its concern about public space, its focus on community engagement, and its efforts to advance the beginning-to-end experience of mobility.

For Coral, the emphasis on residents' wants and needs is especially important at this stage, as connectivity is rapidly changing the urban mobility landscape. She explained that this focus has not always been present in mobility conversations: "It's been documented that previous land use and design choices, when cities and highways were built, had some very negative consequences." Knight's mission is to help cities learn from those previous inflection points and engage people in the conversation about what cities should look like. Ultimately, communities should say how they want these new mobility options to serve their needs.

The goals of the conference included:

- Examining the role of officials at the city, county, and regional levels in taking ownership of various platform efforts.

- Discussing the possibilities for cities to enhance public engagement and trust through connected mobility efforts.

- Helping accelerate adoption of a common set of rules, protocols, and understandings that support connected mobility.

- Creating a space where individuals within that transportation space can discuss the changing demands, tensions, and modalities.

- Providing a channel for technologists, public space folks, policy experts, mobility folks, and legal/data privacy experts to come together and build a more holistic and multidisciplinary mobility vision. 


\section{WHAT CHANGED-HOW DID WE GET HERE?}

Even while cities experienced threshold changes affecting mobility infrastructure, the regulatory and planning frameworks lagged or responded with adaptations that did not fundamentally consider the new connected mobility options and their affect on urban life. For too long, mobility regulation focused on a single mode like taxis and associated issues like barriers to entry and safety, but not around the larger system issues. Cities used to have limited modes of transportation: public transit, private cars, or taxis. Although public transit includes ferries, streetcars, subways, and light rail, the most-ridden form of public transit in the United States is the bus. ${ }^{1}$ However, buses are limited by old routes, federal regulations, and not enough funding for updates. ${ }^{2}$

\section{The Impact of Connectivity on Mobility}

In the past 20 years, the mobility landscape has changed dramatically, catalyzed by considerable changes in the technology available to the consumer and to the provider. The car-share company Zipcar launched in 2000 as an alternative to traditional car rentals and car ownership. Since then, ridesharing TNCs, dockless bikes and scooters, and electric personal vehicles have appeared in cities all over the world. In only two decades, new transportation options have proliferated, creating a menu of choices for urban residents, and a host of new costs and benefits for government.

The ubiquity of mobile phones with high-performing and user-friendly apps, the ability to inexpensively process massive amounts of data, advanced analytics, the presence of IoT devices, high-speed internet, social networking, and shared vehicles all affect how people move through their cities.

As connectivity impacts mobility, cities have also discovered new leverage points, including physical infrastructure, street and curb regulations, licensing, and labor and consumer protection laws. These laws were meant to respond to a particular problem or interest group but are very rarely prompted by consumer groups. Innovative city officials now see how issues across various modes of transit integrate with land use issues like quality of life and livable public spaces.

Technology breakthroughs produce new mobility options and could produce a new regulatory framework. But cities will be unable to take advantage of them 
if they do not update government's antiquated operating system. In order to build equitable, values-driven mobility, governments will need to undergo systemic and structural changes.

\section{Return to Cities, Gentrification; Movement Away from Jobs}

The expansion of mobility options aligns with changing trends in urban density. At the Connected Mobility conference, Santiago Garces, the former chief innovation officer from South Bend, Indiana, and current director of innovation and performance for Pittsburgh, talked about the relationship between transportation and work in previously industrial centers. When factories moved out of cities and into suburbs, they passed an increased transportation cost onto city-dwelling workers. That burden went to the workers without any extra compensation, which meant that workers were unable to easily pick up extra shifts and were more likely to arrive late. This example is discussed in more detail below, but in South Bend, the city explored how the government could push that responsibility back to employers and then assist with covering any gaps.

In other areas of the country, the inverse has been the challenge at hand: jobs are concentrated in city centers and workers are scattered hours away. The failure to build adequate housing accompanied by rising housing costs, most notably in places like San Francisco, have resulted in multi-hour commutes. Many people have a tenuous grasp on economic stability, and much depends on whether they own a car to overcome the vast distance between jobs and affordable housing. This trend has also led to an increase in demand for better transit and last-mile options for commuters. As stated in an important report by the Center for Neighborhood Technology, one needs to consider housing costs as a combination of transit costs in time and money, along with the cost of housing itself. ${ }^{3}$ Women and low-income individuals are particularly affected. ${ }^{4}$

To illustrate this, The Urban Institute mapped "spatial mismatch" in San Francisco, which is the "mismatch between where jobs are located and where job seekers live." The map below is from their 2019 "Too Far from Jobs: Spatial Mismatch and Hourly Workers" report and shows that the concentration of jobs is far from the concentration of affordable living for workers. ${ }^{5}$ 


\section{Spatial Mismatch in the San Francisco Bay Area, 2017}

Note: "Reasonable distance" is 6.3 miles from the population-weighted centroid of each zip code, the average distance between job seekers and jobs for each application in the dataset.

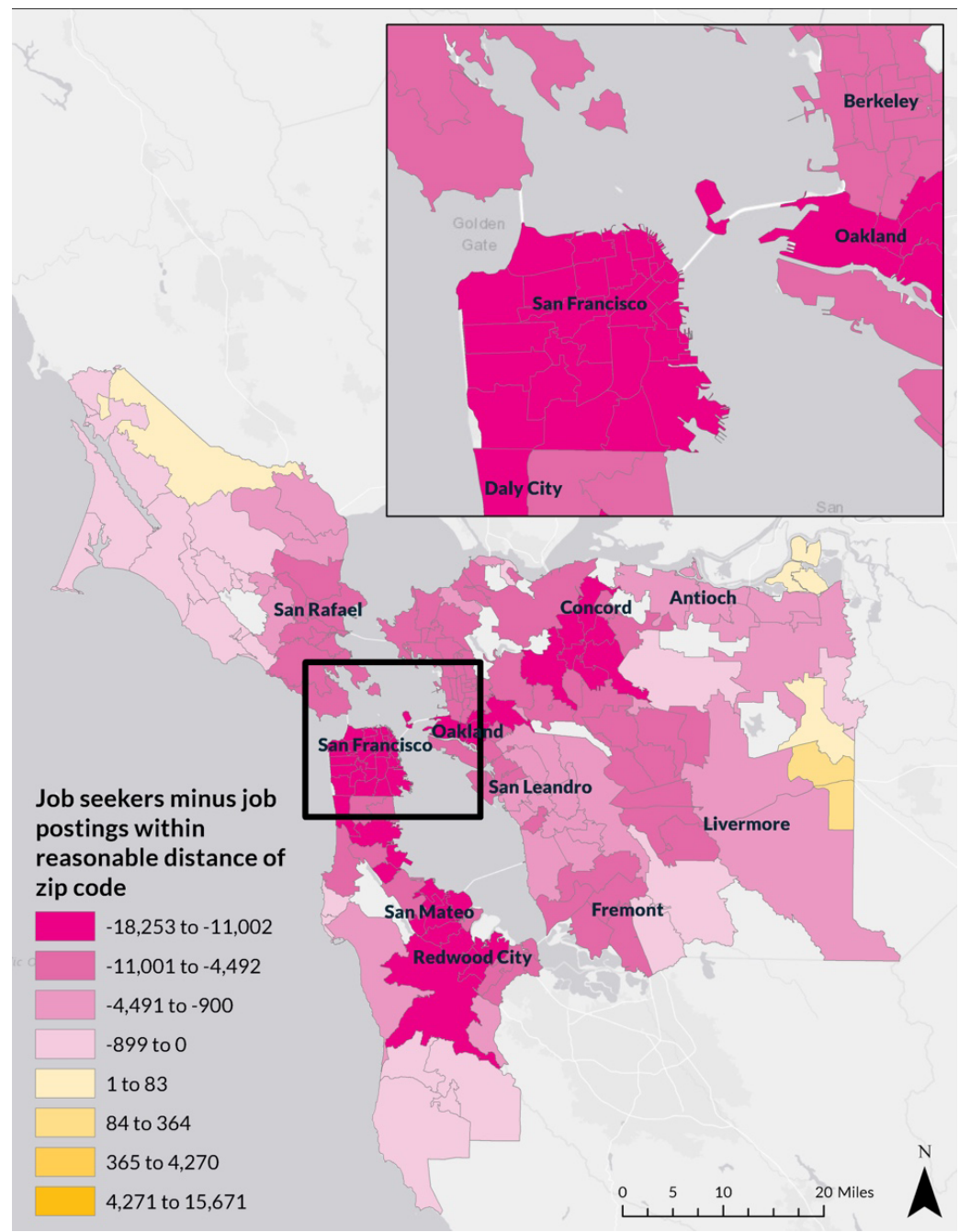

Graphic from The Urban Institute, “Too Far from Jobs: Spatial Mismatch and Hourly Workers.” 


\section{E-Commerce and Delivery}

Online delivery systems are a major disruptor. In October 2019, the New York Times reported that 1.5 million packages are delivered every day in New York City, an extreme example of how connectivity is reshaping mobility. ${ }^{6}$ City residents can order dinner, toilet paper, furniture, alcohol, textbooks, medicine, groceries, and more from their phones, and delivery is usually just a few days-if not a few hours. The same article stated that "households now receive more shipments than businesses," which means that delivery vehicles are pushing into residential neighborhoods not designed for truck traffic and without designated loading zones.

New mobility companies are often involved in the delivery of both goods and people. For example, Uber is not just a ride-hailing company-it also conducts deliveries through the Uber Eats platform. Heather Marx, the director of Downtown Mobility for the Seattle Department of Transportation, has seen poor driving practices on streets crowded with construction due to random drop-offs and unsafe traffic maneuvers. Her office is gathering data on how many cars are circling in the city, waiting for delivery or passenger orders, although capturing this data is proving difficult. Marx acknowledged the obvious benefit of delivery and ride hailing, such as allowing people to live without owning cars, but pointed out that "just because you're not driving your own car, doesn't means you're not driving in a car." Seattle is also experimenting with geofencing that prevents Uber and Lyft from operating on certain streets in order to reduce congestion and increase pedestrian safety.

Other companies are only involved in transportation of goods; Amazon is the largest internet services and retail company by revenue and popularized quick delivery with Prime two-day shipping. And there is now same-day and one-day delivery available for many Prime members. ${ }^{8}$ At the Connected Mobility conference, Kevin Webb, co-founder and director of the Open Transport Partnership, predicted that in five years Amazon will own and operate the largest private commercial fleet in the US, outnumbering UPS's global fleet, second only to the US Postal Service. He described their model as "potentially even more disruptive" for city streets than existing ride-hailing businesses and package delivery services, as it combines potentially problematic aspects of both. The complexity of these changes will require coordination beyond traditional transportation stakeholders. 


\section{Effect of Digital Maps}

Digital maps have had a profound effect on transit behaviors. At the conference, Seleta Reynolds, the general manager for the Los Angeles Department of Transportation, brought up an article in Los Angeles magazine that reported on some volunteer map editors for Waze who were "drunk on digital nerd powers" and who opened and closed streets on the Waze app or used the app to misreport congestion. ${ }^{9}$ Reynolds pointed out that "that would never be allowed for private citizens in the physical world" and asked "why it is allowed in the digital" one.

In a follow-up interview, Reynolds expounded, saying that at its most basic level, "the city needs to have the same ability and authority in the digital realm as it has in the physical realm.” A main concern is safety: “No app ought to be able to override the way that traffic control devices work." Reynolds has the authority to open and close streets in the physical realm when there are emergencies, and she maintains that she must be able to do that in the digital realm as well.

Her other concern is around equity; who is editing these maps and closing off streets and regulating speeds? "When we get into that version in the digital world, with a navigation app telling people that they need to go slower or they can't use certain streets or others, we've put ourselves in the position of picking winners and losers. So, then it becomes very important to have very clear and transparent public criteria-that are publicly debated, discussed, and agreed upon-for doing that."

In a thread on Twitter, Kevin Webb stated that "it's not about the map, it's fundamentally about how we define and express people's right to space." The world of digital maps can accurately reflect the physical realm and uphold the democratic processes that allow someone like Reynolds to do her job or it can create a parallel, unregulated existence.

\section{Recognition of High Cost of Parking and the Value of the Curb}

For several decades, planning departments required substantial parking facilities for new apartments in urban areas; developers needed to include 1.5 spaces per apartment, to be built in decks or underground at great cost. These planning decisions helped make housing more expensive. As millennials move into denser areas, cities across the country are seeing that density near public transit significantly furthers 
quality of life goals. In addition, new mobility solutions are changing how much parking buildings need and are also transforming curb space into a valuable asset to be managed. In response, cities are looking at dynamic pricing models for curbs and parking spots. Since the hidden cost of free parking is passed along to all residents, even those without cars, some cities are exploring how to right-price spaces and use the parking income to support public transit improvements. ${ }^{10,11}$

Yet parking (and its cousin, stopping to drop off) does not relate only to cars. New modes have also changed how city curbs are used. Ride-hailing vehicles may not need to park but they do need to load and unload passengers. Micromobility needs parking, as right now many dockless bikes and scooters are strewn on sidewalks. And, while connected mobility could help cities move away from traditional car parking spaces it will require new curb planning and regulations.

As mobility modes change, so does the physical landscape. Spaces that were clearly defined for pedestrians are now used by micromobility vehicles, and any part of the street can become an impromptu parking space due to ride-hailing services. City streets are slowly adapting; instead of being planned around cars, they need to be flexible and oriented toward the many kinds of new mobility. 


\section{WHAT'S AT STAKE: PUBLIC VALUE GOALS AND MOBILITY}

Agency officials understandably spend their time focused on metrics relevant to their jobs and for which the public holds them responsible: on-time service, cleanliness of public areas, time it takes to get from $A$ to $B$, and safety rates. Yet in the conference, attendees filtered their approach to emerging mobility issues through a values lens, relating to a larger set of public goals and objectives. We look below at the important public values that mobility planning affects.

\section{Community Engagement and a User-Centric Design}

Managing mobility means managing a host of different, often conflicting, community voices. And too often it means a process where professionals attend meetings to gather input on just one aspect of transportation, such as route planning. Yet the "mobility as a service" management world, with its overwhelming data, demands not only that residents participate in large numbers but that the new system be designed around their needs and interests. The phenomenon of regulatory capture has in the past frequently applied to mobility where private companies like taxi fleets influence agencies in a way that helps create barriers to entry or other advantages. More recently, a private company will use its lobbying influence at the legislative branch of the city, state, or federal government to preempt proper planning. Both of these situations in effect stymie public engagement. It is very different engagement when the regulator makes the user central to the policymaking process.

This process requires much more participation and data. "Most of the community engagement in cities is a part-time afterthought," Mike Sarasti, the chief innovation officer and director of innovation and technology for Miami, declared at the conference. Engagement around public transit is complex, because it touches on values like sustainability, public safety, and equity. It is also complicated because it often involves private companies and citizens on all sides of the debate. In Louisville, Kentucky, private citizens self-designated their sidewalks scooter-free zones by contacting the companies, a public-realm change that occurred without the knowledge of city officials. 
Since traditional public input often involves small samples of competing points of view, some city officials believe that inclusive service can only come from inclusive outreach measured against the city's demographic statistics. In Memphis, Tennessee, community engagement was a large part of Transit Vision, their future transit planning process. Justin Entzminger, the director of Innovate Memphis, knew that they would need to go out into the community and tailor their engagement toward transit users while seeking a representative sample. The Innovate Memphis team did not simply host their own outreach programs; instead, they attended community meetings, parades, and public gatherings where they could talk about transit with the public. They compared how representative their in-person outreach and surveys were to the city's population. For instance, Memphis is majority African American, and Innovate Memphis eventually had feedback from a pool of respondents that was 70 percent African American. The income levels were representative of the city as well. Only bus riders were disproportionately overrepresented as they make up only two percent of the general population but are an important voice around transit use and reform.

Other cities are also exploring newer forms of outreach and inclusion. At the conference, Santiago Garces discussed how factory relocation made commuting difficult and uncertain for workers in South Bend. The local government wanted to find ways to assist workers, so officials went on commuting journeys "to capture the intangibles" and better understand how residents were making transportation decisions. This helped the city devise Commuter Trust, a low-cost multimodal transit pilot for local employees that helps them access ride-hailing and bus passes at reduced cost. The program is a public-private partnership and is supported by the Bloomberg Philanthropies Mayors Challenge.

Both successful engagement methods prioritized rider voices and experiences, and specifically engaged residents who were fully familiar with the realities of existing forms of transit. Gathering feedback and designing a project around the user becomes more difficult when the technology is new and the implications speculative. According to Eric Roche, chief data officer for Kansas City, Missouri, "one of the mistakes we often make is to ask for feedback right away." Especially with micromobility, cities need time to collect data and residents need time to experience the pros and cons. In the South Bend example, residents could respond based on their actual experiences, 
but if community outreach precedes deployment, reaction will often be based on conjecture. If the new service is well-established, the community feedback is more nuanced and grounded in user reality. It requires a delicate balance, because community engagement must not be an afterthought, but it does need to derive from actual user experience.

According to Lilian Coral, one of the age-old questions in cities is "who gets to be a part of designing the vision?" Other modalities wrestle with this question, as well, but inclusivity and engagement are especially important for mobility because "there's no one it doesn't affect." The feedback and ideas that come from some of the difficult conversations are crucial to incorporate and can help cities encourage private companies to adhere to public good and values, through what Coral describes as "the power of the voice of the people."

\section{Improved Public Safety}

Maintaining the health and safety of citizens is one of the fundamental goals of city governments. Transportation safety encompasses a dizzying array of modes (biking, walking, driving), spaces (sidewalk, street, curb), individuals (driver, pedestrian), and infrastructure (traffic signage, lighting, speed limits). While autonomous cars are marketed as the vehicle to end vehicle deaths, there are many other safety elements to consider.

At the conference, Janette Sadik-Khan, the former commissioner of the New York City Department of Transportation and current principal with Bloomberg Associates, stated that "we could just redesign streets and control for speed, and do that right now" to make streets safer. But she acknowledged that "infrastructure is hard to do, and smart parking, street closings, and congestion pricing took a lot of blood, sweat, tears, and bad headlines" in New York to accomplish.

According to Sadik-Khan, "the tech piece is almost the easier thing." Where this is the case, cities can use technology to help make changes and increase safety through data. For instance, smart sensors can monitor traffic intersections and identify dangerous zones, and that data can inform new policies or prompt new infrastructure that increases driver and pedestrian safety. Or geolocation data on public buses can help make the case for congestion pricing or street closures. 
The introduction of new mobility can also shift how cities view road safety. As a Vision Zero city, Minneapolis is working to eliminate all traffic crash deaths in the next ten years by focusing on the "most vulnerable roadway users-people walking and people biking." Robin Hutcheson, the director of public works for the city of Minneapolis, helped evaluate scooter companies over the summer by asking them to "demonstrate how your presence will support our goals," one of which is safety. Out of the seven companies evaluated, three were invited to roll out in Minneapolis. The introduction of these new mobility modes could shift who the city views as their most vulnerable, but according to Hutcheson, "the perception is that people are crashing all the time on scooters, but the reality is, they aren't." With the introduction of new mobility, data is crucial; according to Hutcheson, "the perception of a decrease in safety-I don't think that's a reality." While it will take a few years for the safety data that includes scooters to be reliable, it is important to Hutcheson that perception does not supersede data.

Data helps cities understand where to direct their attention in such a rapidly changing landscape. For example, another aspect of public safety that has been affected by connected mobility is the personal safety of new-mode users, which encompasses crimes against ride-hail users. In December 2019, Uber released its first safety report, which reported 5,981 sexual assaults in 2017-2018 (for this report, sexual assault was considered defined as any physical or attempted physical contact that is reported to be sexual in nature and without the consent of the user). ${ }^{12}$ City officials, who may not have understood the full scope of this issue before this report, are now struggling to find the levers that will keep residents safe.

\section{Improving Public Health and Sustainability}

Over the last decade, the role of cities as agents for environmental action has changed dramatically, creating new opportunities as well as mandates related to climate, public health, and transit. Until about ten years ago, officials viewed climate as a global issue to be approached by nations. Then, in 2007, New York City Mayor Michael Bloomberg released PlanNYC: a comprehensive local action sustainability plan. ${ }^{13}$ These steps in New York, and earlier ones in Seattle, inspired cities to become much more active in structuring collaborations that could produce environmental impact. The largest cities 
around the world have created their own collaboration, participating in the $\mathrm{C}_{40} \mathrm{O}$ network of megacities working together to act on climate change.

The transportation sector is one of the largest contributors of greenhouse gas emissions, with light-duty vehicles like cars and SUVs responsible for 59 percent of transportation-related emissions. ${ }^{14}$ Public transit, depending on load levels, can produce fewer emissions per person than a private automobile, and many micromobility options are more environmentally friendly than cars. ${ }^{15}$ Mass transit also has "substantially lower crash rates and lower crash severity" ${ }^{16}$ compared with cars and is also linked to higher rates of physical activity and walking. ${ }^{17}$ Mobility vividly connects to quality of life in broader ways than just how quickly one gets across town. It involves walking, biking, shared rides and transit-all designed with an eye towards contributing to a healthier and more sustainable environment.

2017 U.S. GHG Emissions by Sector

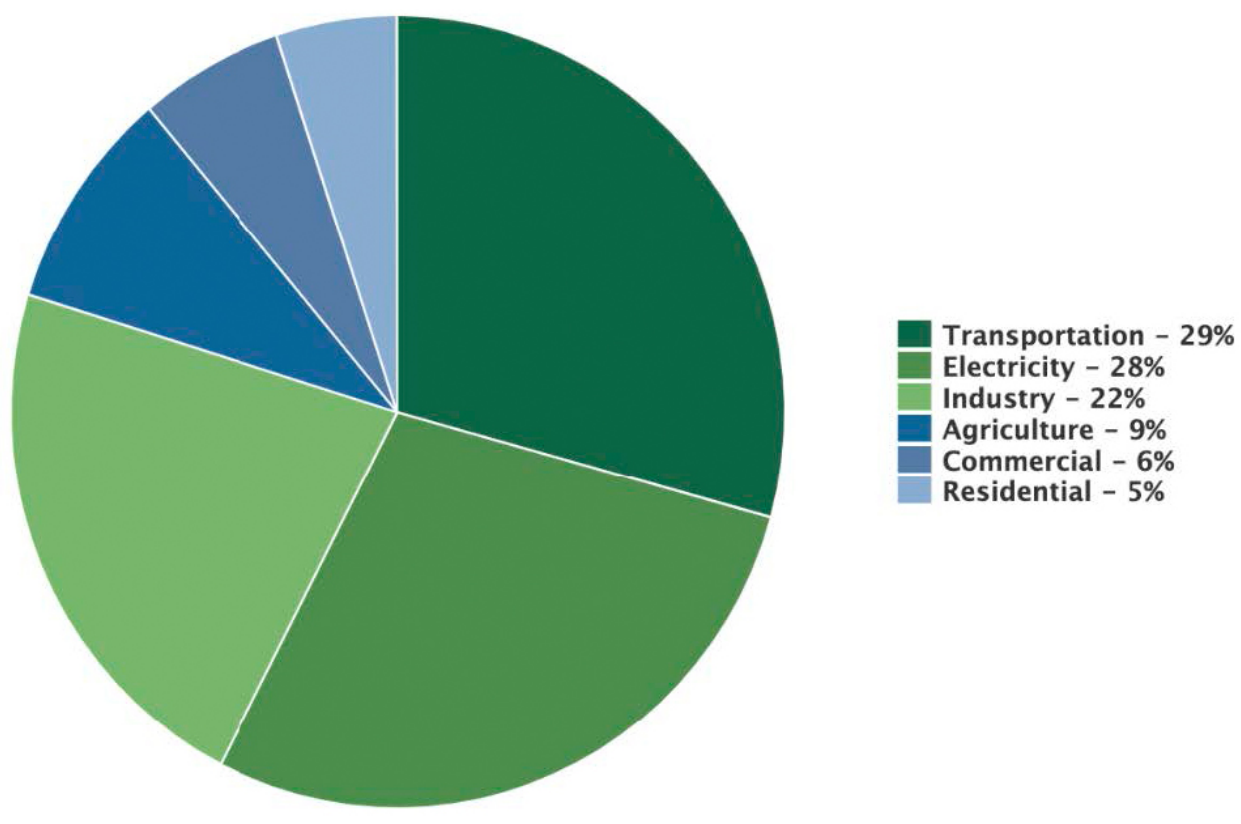

Graphic from the Environmental Protection Agency, “Fast Facts on Transportation Greenhouse Gas Emissions.” 
For many cities, the new connected mobility is an opportunity to decrease car dependency and improve public health and environmental outcomes. This is particularly true in Los Angeles, where low-income residents and particularly residents of color are at a greater risk for illnesses like asthma due to their increased exposure to vehicle-related air pollution. Studies of Southern California have shown that "minority and high-poverty neighborhoods in the region bear over two times the level of traffic density compared to the rest of the region." ${ }^{18}$

Seleta Reynolds focuses on public health and health disparities in Los Angeles. She wants to improve health outcomes by reducing single-occupancy vehicles, and to do so she is working with new mobility companies. However, Reynolds has different levels of influence with different types of connected mobility. Thanks to the fact that she permits micromobility companies, she can influence their data-sharing and more likely hold them accountable "to the provision of equitable services." But Reynolds does not have that same relationship with ride-hailing businesses and cannot guarantee that they will help address health disparities by providing rides in underserved areas.

Reynolds also recognizes that "incentives by themselves have a pretty limited utility," because when the Los Angeles Department of Transportation offered a reduced per-vehicle cost and higher vehicle caps if micromobility companies deployed scooters among the disadvantaged communities of San Fernando Valley-which "has some of the worst air quality in the city"-only one out of the eight companies in Los Angeles took advantage of that incentive.

According to Reynolds, "what you have are private mobility companies that are making decisions purely through a profit lens, through an accountability to shareholders lens, and not accountability to the general public. So, you're sort of trusting that those things are aligned, but they increasingly are not." She feels that the public sector has a stronger role to play, and the city does influence where it can around street redesign and sustainable procurement; for example, Los Angeles just purchased the largest US fleet of electric buses. "Eventually we will have to turn to legislative remedies to create more accountability from the private sector," said Reynolds. Connected mobility can address public health inequities, if the right levers exist to align private company goals with public ones. 


\section{Advancing Equitable Service Delivery and Access}

As new mobility modes arrive in cities, officials believe that these modes have the potential to help reduce transit inequities-or exacerbate them. In South Bend, the Commuter Trust program is helping to subsidize ride-hailing to address long, irregular commutes for factory workers. But in cities like Los Angeles, officials are struggling with ride-hailing companies that have no obligation to operate in underserved areas or make their apps available to people who are unbanked.

In Detroit, scooters are currently piloted under a memo of interpretation. Justin Snowden, the smart mobility strategist in the Mayor's Office of Mobility Innovation, explained that this memo was based on two laws in the city code that were reinterpreted for scooters but that are not legally binding. In the memo, the city requested a split of roughly $70 / 30$, with most of the scooters downtown and the rest located in underserved areas. Snowden described that attaining this balance as an ongoing struggle. According to Snowden, because the memo does not have the force of a formal regulatory mechanism, like an ordinance, most of the scooter operators "aren't really adhering to that request." He anticipates stronger language to make the companies adhere to this equity split when the city finishes the pilot and puts out a formal ordinance.

Snowden is also concerned about access, which he broadly defines. Not only does he want geographic accessibility but he wants the companies to consider other types of users. There are plenty of Detroit residents who are unbanked or without credit cards, so he has asked scooter companies to investigate offering a different payment method. There are also residents who do not have smartphones with data plans, so he is proposing the development of a Bluetooth or SMS unlock capability for the scooters. The scooter companies understand his concerns but are asking for a cap increase in exchange for any of these improvements.

City officials understand that the companies have obligations to shareholders and are not necessarily driven by the same public values. Through a formal partnership, cities could reinvest the money charged to the companies and create vouchers or transit passes for residents that are underserved. They could also create revenue from new curb-sharing agreements, which would charge TNC for loading and unloading, and then use that money to subsidize rides for low-income residents or who are disabled. 
In an interview with Seleta Reynolds, she advocated that the:

really important step that we're only just beginning to explore in transportationis atonement. When you go into a community that is surrounded by freeways but trapped from opportunity by low levels of auto ownership, combined with really diffuse land use patterns that make it almost impossible to reach jobs on a consistent basis without a car-all of these are legacies of decisions made over several decades by people who were in my seat, or in seats above me, in elected office at the state or national level.

Cities that want to use the atonement and climate justice lens will need to ask important questions like "Are our departments reflective of the communities we're working with?" and "Are we exploring new options for micromobility and public transit, and are these options equitably distributed?" In order to answer these questions, cities will need a host of specific data like air quality measures, car ownership statistics, and rates of childhood asthma. And most importantly, cities will need to learn how to engage members of the affected communities and co-create solutions.

\section{Improving Land-Use Planning and Parking Policy}

Research shows that many cities have significantly more parking than needed, with places like Philadelphia having 3.7 spaces per household and up to 19.4 parking spaces per household in Des Moines, lowa. ${ }^{19}$ Architects and urban planners are already reimagining land that is currently used for parking, as private car ownership is predicted to decline and autonomous vehicles are poised to disrupt traditional parking patterns. ${ }^{20}$ 


\section{Traced Surface Parking Landcover in Philadelphia}

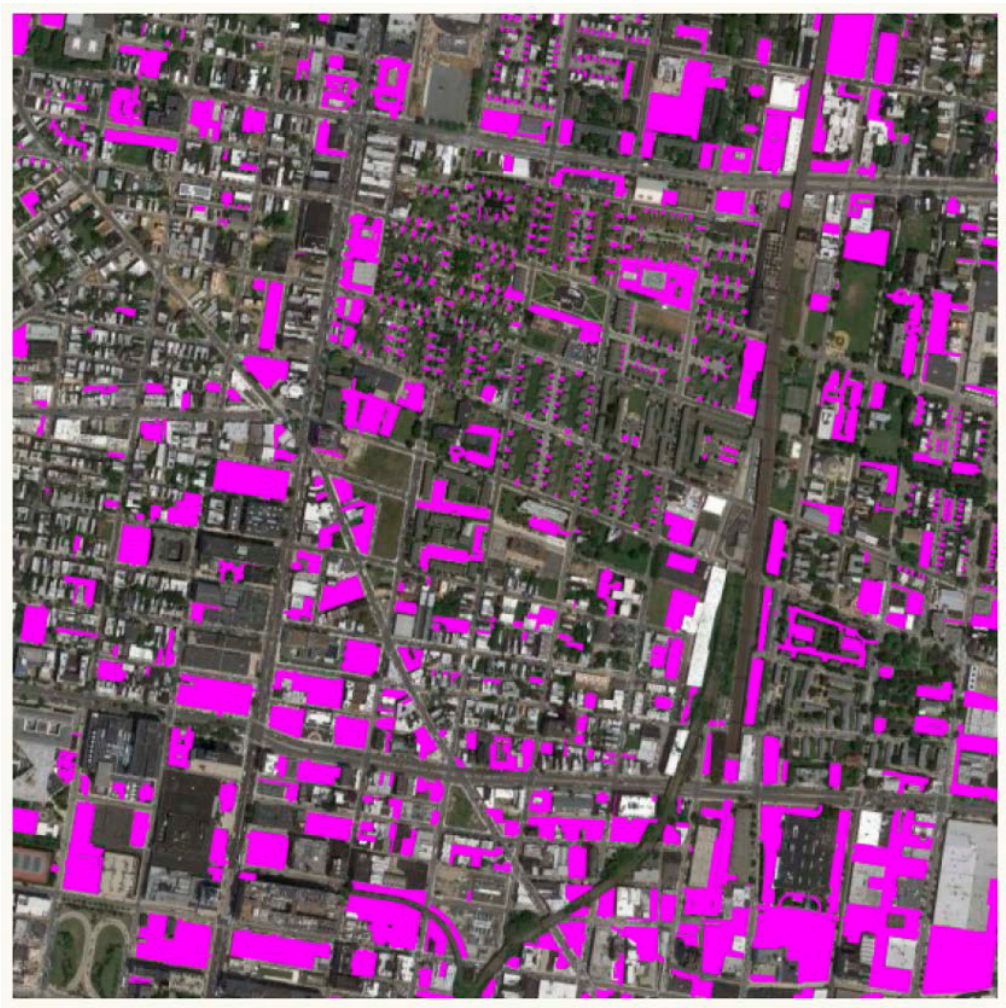

Image from the Research Institute for Housing America, "Quantified Parking: Comprehensive Parking Inventories for Five U.S. Cities."

The Rocky Mountain Institute, in collaboration with the Robert Wood Johnson Foundation, is advancing the concept of MOD cities, where "MOD" means not only "modular" and "modifiable" but is also an acronym for "mobility-oriented development." A key feature of the MOD city is the ability to physically transform depending on demand.

For example, during the morning and evening commute, former car lanes are allocated for bikers and walkers. And parking spaces are less necessary, thanks to microand connected mobility, so those former parking spaces are freed up for scooter or bike corrals and social spaces. During the day, more street space is flexed into gathering areas and, at night, the streets and parking spaces are available for electric vehicle charging, mobile food service, and pop-up modular housing. 
Whether these exact streets come to pass, it is obvious that the introduction of micromobility and the potential for autonomous vehicles has changed how city land is oriented. Donald Shoup, distinguished research professor of urban planning in the Luskin School of Public Affairs at the University of California, Los Angeles, has been researching parking regulations for over four decades. He advocates that developers should be allowed to eliminate off-street parking requirements, and that cities should right-price for on-street parking and then spend the meter revenue on visible street improvements.

\section{What's at Stake}

Transportation has entered a new phase, and it is crucial that cities prioritize public values when planning and evaluating mobility. As the landscape changes, an intentional values lens should be used when considering new forms of mobility, updates to older modes, and changes to infrastructure. City officials must have metrics for evaluating progress against those values, and the values should to be informed by data and public engagement work.

In this paper we summarize the large-scale changes affecting not just cities and their residents but the very nature of transportation itself. Those changes need to be addressed through the important lenses of equity, sustainability, better land use, and public health and safety. Officials face daunting complexity in taking on these challenges but even small steps towards a future connected mobility world promises dramatically improved results.

\section{NEXT STEPS}

In a future paper, we will assist cities with the application of values lenses. We will clarify the questions they must ask, what data they will need, and who to engage, so city governments can effectively apply the different lens to their mobility work. There

are high stakes for each of the lenses described in this paper; now is the moment to influence and shape mobility in accordance with these values and goals. 


\section{APPENDIX: CONFERENCE ATTENDEES}

Joe Barr, Director of Traffic, Parking, and Transportation

City of Cambridge, Massachusetts

Robin Chase, Transportation Entrepreneur

Zipcar, Veniam, NUMO

Lilian Coral, Director of National Strategy + Technology Innovation

Knight Foundation

Stefanie Costa Leabo, Chief Data Officer

City of Boston, Massachusetts

Carlos Cruz-Casas, Assistant Director of Strategic Planning

Miami-Dade County, Florida

Stephanie Dock, Research Program Administrator

District of Columbia

Brian Donoghue, Director of Civic Innovation

City of South Bend, Indiana

Sharon Feigon, Founder and Executive Director

Shared-Use Mobility Center

Jascha Franklin-Hodge, Executive Director

Open Mobility Foundation

Santiago Garces, Director of Innovation \& Performance, Chief Innovation Officer

City of Pittsburgh, Pennsylvania

Ariel Gold, Data Program Manager

US Department of Transportation

Stephen Goldsmith, Daniel Paul Professor of the Practice of Government and Director of the Innovations in Government Program

Harvard Kennedy School

Art Guzzetti, Vice President - Policy and Mobility

American Public Transportation Association

Kat Hartman, Director of Innovation \& Emerging Technology

City of Detroit, Michigan 
Meera Joshi, outgoing Commissioner

New York City Taxi and Limousine Commission

Sean McDonald, Co-Founder

Digital Public

Nicholas Mosquera, Project Team

Bloomberg Associates

Seleta Reynolds, General Manager of the Los Angeles Department of Transportation

City and County of Los Angeles, California

Eric Roche, Chief Data Officer

Kansas City, Missouri

Janette Sadik-Khan, Founding Principal

Bloomberg Associates

Andrew Salzberg, Loeb Fellow

Harvard University

Suthee Sangiambut, Applied Research Lead

OpenNorth

Mike Sarasti, Director of Innovation and Technology

City of Miami, Florida

Michael Schnuerle, Data Officer

City of Louisville, Kentucky

Andres Sevtsuk, Charles and Ann Spaulding Career Development Associate Professor

Massachusetts Institute of Technology

Emily Warren, Venture Partner

Fontinalis Partners

Kevin Webb, Co-Founder and Director

Open Transport Partnership

David Zipper, Visiting Fellow

Harvard Kennedy School 


\section{Endnotes}

1. "National Transit Database Provides Key Stats on Public Transportation in the U.S." US Department of Transportation, retrieved December 7, 2019, https://www.transportation .gov/connections/national-transit-database-provides-key-stats-public-transportation-us.

2. English, J. "Why Did America Give Up on Mass Transit? (Don’t Blame Cars.)," CityLab, December 7, 2019, https://www.citylab.com/transportation/2018/08/how-america-killed -transit/568825/.

3. "Safe, Decent, and Affordable: Transportation Costs of Affordable Housing in the Chicago Region," The Center for Neighborhood Technology, January 2012, retrieved December 6, 2019, https://www.cnt.org/sites/default/files/publications/CNT_SDA.pdf.

4. Methipara, J. C., "Brief: Mobility Challenges for Households in Poverty," Federal Highway Administration, 2014, retrieved November 20, 2019, https://nhts.ornl.gov/briefs/PovertyBrief .pdf.

5. Stacy, C., B. Meixell, and S. Lei, “Too Far from Jobs: Spatial Mismatch and Hourly Workers." The Urban Institute, February 21, 2019. Retrieved January 2, 2020, https://www.urban.org /features/too-far-jobs-spatial-mismatch-and-hourly-workers

6. Haag, M., and W. Hu, "1.5 Million Packages a Day: The Internet Brings Chaos to N.Y. Streets," The New York Times, October 27, 2019, https://www.nytimes.com/2019/10/27/nyregion /nyc-amazon-delivery.html.

7. “2019 Fortune Global 500," Fortune, retrieved December 7, 2019, https://fortune.com /global500/2019/.

8. “Prime FREE Same-Day and One-Day,” Amazon.com, retrieved December 7, 2019, https:// www.amazon.com/Prime-FREE-Same-Day-Delivery/b?ie=UTF8\&node $=8729023011$.

9. Stuart, G., "Waze Hijacked L.A. in the Name of Convenience. Can Anyone Put the Genie Back in the Bottle?" Los Angeles Magazine, August 20, 2019, retrieved November 17, 2019, https://www.lamag.com/citythinkblog/waze-los-angeles-neighborhoods/.

10. Schmitt, A. "Americans Can't Afford the High Cost of Parking Requirements," Streetsblog USA, June 6, 2016, https://usa.streetsblog.org/2016/06/06/americans-cant-afford -the-high-cost-of-parking-requirements/.

11. Bliss, L. "Parking Policy Is Hot, Thanks to Donald Shoup," CityLab. May30, 2018, https://www .citylab.com/transportation/2018/05/parking-is-sexy-now-thank-donald-shoup/560876/.

12. “2017-2018 US Safety Report," Uber Technologies, Inc., December 2019, retrieved December 7, 2019, https://www.uber-assets.com/image/upload/v1575580686/Documents/Safety /UberUSSafetyReport_201718_FullReport.pdf. 
13. Feifel, K., "PlaNYC: A Comprehensive Sustainability Plan for New York City," Climate Adaptation Knowledge Exchange, April 7, 2010, retrieved November 23, 2019, https://www .cakex.org/case-studies/planyc-comprehensive-sustainability-plan-new-york-city.

14. "Fast Facts on Transportation Greenhouse Gas Emissions [Overviews and Factsheets]," US Environmental Protection Agency, August 25, 2015, retrieved December 7, 2019, https:// www.epa.gov/greenvehicles/fast-facts-transportation-greenhouse-gas-emissions.

15. "Public Transportation's Role in Responding to Climate Change," US Department of Transportation, January 2010, retrieved November 14, 2019, https://www.transit.dot.gov/sites /fta.dot.gov/files/docs/PublicTransportationsRoleInRespondingToClimateChange2010 .pdf.

16. "Expand Public Transportation Systems and Offer Incentives," US Department of Transportation, October 2015, retrieved November 17, 2019, https://www.transportation.gov /mission/health/Expand-Public-Transportation-Systems-and-Offer-Incentives.

17. She, Z., D.M. King, and S.H. Jacobson, "Is Promoting Public Transit an Effective Intervention for Obesity?" Transportation Research Part A: Policy and Practice, 119: 162, 2019, http:// dx.doi.org/10.1016/j.tra.2018.10.027.

18. Houston, D., J. Wu, P. Ong, and A. Winer, "Structural Disparities of Urban Traffic in Southern California: Implications for Vehicle-Related Air Pollution Exposure in Minority and High-Poverty Neighborhoods," Journal of Urban Affairs, 26(5), 565-592, 2014, https://doi .org/10.1111/j.0735-2166.2004.00215.x.

19. Scharnhorst, E., "Quantified Parking: Comprehensive Parking Inventories for Five U.S. Cities," Research Institute for Housing America, 2018.

20. Johnson, C. and J. Walker, "Peak Car Ownership Report," Rocky Mountain Institute, 2016, retrieved December 2, 2019, https://rmi.org/insight/peak-car-ownership-report/. 


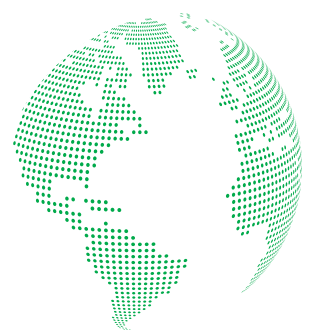

A publication of the

Ash Center for Democratic Governance and Innovation Harvard Kennedy School 79 John F. Kennedy Street

Cambridge, MA 02138

617-495-0557 